data: 1) commercial insurance, 2) Medicaid insurance, and 3) Medicare insurance were utilized.

Methods: The data source was Truven Health MarketScan ${ }^{\circledR}$ Databases, containing medical service and prescription drug claims from commercial, Medicaid (11 states) and Medicare supplemental insurance plans for $>80 \mathrm{M}$ US patients. CLE cases were identified by presence of $\geq 2$ service dates with an ICD- 9 code 695.4 on unique dates $\geq 28$ days apart during the study period (Jan 1 2010-Dec 31 2014). For the most recent study year, the 5 most frequent comorbidity categories were reported using Clinical Classifications Software (CCS) Level 2 groupings. Similarly, the 5 most frequent pharmacy dispensings among CLE cases in 2014 were reported.

Results: In the Commercial, Medicaid, and Medicare claims data, 35,781, 7,361 and 5,594 CLE patients, respectively, were identified. CLE cases were $>80 \%$ female with $<6 \%$ aged $<19$ (Table). The most frequent CCS category (in all databases except Medicare) was CCS 13.7 (SLE and connective tissue disorders including systemic sclerosis, sicca syndrome, dermatomyositis, and polymyositis) where $63.1 \%, 76.6 \%$, and $59.4 \%$ of CLE cases in the Commercial/Medicaid/Medicare data, respectively, had $\geq 1$ claim. The most frequently-dispensed medication was corticosteroid hormone $(62.5 \%, 72.1 \%$, and $62.3 \%$ in the Commercial/Medicaid/Medicare data), while antimalarials were used by $58.3 \%, 55.9 \%$, and $52.1 \%$ of CLE patients in the 3 databases, respectively.

Table 1. Demographics of CLE patients, by database, 2010-2014

\begin{tabular}{lccc}
\hline & Commercial & Medicaid & Medicare \\
\hline $\mathrm{N}$ & 35,781 & 7,361 & 5,594 \\
Mean (Median) Age & $46.6(49)$ & $44.1(44)$ & $71.9(71)$ \\
Age category & & & \\
$\quad \leq 18$ & $2.2 \%$ & $5.3 \%$ & $0.0 \%$ \\
$19-30$ & $9.1 \%$ & $15.1 \%$ & $0.0 \%$ \\
$31-45$ & $29.5 \%$ & $32.3 \%$ & $0.1 \%$ \\
$46-60$ & $47.9 \%$ & $33.1 \%$ & $2.5 \%$ \\
$61-64$ & $10.7 \%$ & $5.4 \%$ & $1.9 \%$ \\
$65+$ & $0.7 \%$ & $8.8 \%$ & $95.5 \%$ \\
$\%$ Female & $84.8 \%$ & $89.7 \%$ & $81.2 \%$ \\
\hline
\end{tabular}

Conclusions: Our results document a low relative burden of pediatric CLE. Notably, 23 to $41 \%$ of CLE patients did not have a claim for SLE or other connective tissue disease. Limitations include the inability of code 695.4 to distinguish between CLE subtypes, including discoid and subacute cutaneous lupus.

Disclosure of Interest: S. Hall Shareholder of: Biogen, Employee of: Biogen, L. Li Shareholder of: Biogen, Employee of: Biogen, S. Eaton Shareholder of: Biogen, Employee of: Biogen, C. Musselli Shareholder of: Biogen, Employee of: Biogen, A. Dilley Shareholder of: Biogen, Employee of: Biogen

DOI: 10.1136/annrheumdis-2017-eular.5402

\section{AB1157 PREVALENCE OF MUSCULOSKELETAL DISORDERS AMONG GARMENT INDUSTRY WORKERS IN BANGLADESH}

S.A. Haq, N. Shazzad, S. Ahmed, A.Z. Al-Qadir, A. Shahin. Rheumatology, Bangabandhu Sheikh Mujib Medical University, Dhaka, Bangladesh

Background: Garments industry is flourishing in many developing countries. Attention is often not paid to ergonomics. It is plausible that the prevalence of musculoskeletal (MSK) pain may be high among garments workers.

Objectives: To estimate the prevalence of symptoms and disorders (MSD) among garment workers in Bangladesh.

Methods: This cross sectional study was carried out among 350 workers in two garment factories by face-to-face interview. The COPCORD (Community Oriented Program for Control of Rheumatic Disorders) methodology was adopted for the survey.The workers were classified into cutting, sewing, finishing and quality control operators. Trained interviewers identified subjects with musculoskeletal pain. Trained internists and rheumatologists examined the positive respondents. Results: The point prevalence of musculoskeletal pain was $61.71 \%$. The parts commonly affected during the preceding 7 days of interview in the whole group were shoulder (17.9\%), lower back (15.2\%), neck (13.8\%) and knee (10.8\%). The cutting operators suffered more from back (15.4\%), neck (15.4\%) and lower limb (11.5\%); sewing operators from lower limb (12.4\%), back (8.5\%) and upper $\operatorname{limb}(7.7 \%)$; finishing operators from lower limb (50\%) and quality control group from back pain (50\%). Multiple regional pains were more frequent $(n=155)$ among all operators. The sewing and cutting operators suffered from multiple regional pains more than other operators. The prevalence of Rheumatoid arthritis (RA) $0.9 \%$, spondyloarthropathy (SpA) $1.42 \%$, undifferentiated arthritis (UA) $1.1 \%$, nonspecific low back pain (NSLBP) $4.6 \%$, soft tissue rheumatism (STR) $3.7 \%$, osteoarthritis (OA) $0.9 \%$ and lumbarspondylosis $1.1 \%$.Nonspecific pain was the commonest condition (63.71\%).

Conclusions: Rheumatic disorders are common causes of morbidity, disability, and work loss among the garment workers of Bangladesh where male and female workers are almost equally affected. Multiple regional involvementsare common in this occupational group. Mechanical disorders are the commonest.

Disclosure of Interest: None declared

DOI: 10.1136/annrheumdis-2017-eular.1966

\section{AB1158 PREVALENCE OF COMORBIDITIES IN PSORIATIC ARTHRITIS: A CROSS-SECTIONAL STUDY}

T. Gudu, A. Peltea, M. Abobului, A. Balanescu, F. Berghea, V. Bojinca,

A. Borangiu, C. Constantinescu, L. Groseanu, M.M. Negru, D. Opris-Belinski,

D. Predeteanu, I. Saulescu, V. Vlad, R. Ionescu. Rheumatology, Sf Maria

Hospital, UMF Carol Davila, Bucharest, Bucharest, Romania

Background: Psoriatic arthritis (PsA) is associated with important comorbidities: cardiovascular, gastro-intestinal, infectious, malignant, and psychiatric [1, 2]. However, they are less studied in PsA compared to other chronic inflammatory arthritis.

Objectives: The objective of this study was to calculate the prevalence of comorbidities and risk factors in a cohort of PsA patients.

Methods: This was an observational cross-sectional study, including consecutive, unselected adult patients, with a diagnosis of PsA according to their rheumatologist. Data collected: demographical, clinical (affected joints, current psoriasis, axial involvement, enthesitis, dactylitis), biological (acute phase reactants), and treatment related (nonsteroidal anti-inflammatory drugs, synthetic remissive drugs and biologics). Data on comorbidities and risk factors were collected according to the European League Against Rheumatism (EULAR) recommendations on reporting comorbidities in chronic inflammatory rheumatic diseases in daily practice [3].

Results: In all, 129 PsA patients were included: 77 (59.7\%) women, mean age \pm standard deviation $53.5 \pm 11.8$ years, disease duration $7 \pm 7.4$ years; $53(41.1 \%)$ had axial involvement, 33 (25.6\%) dactylitis, 18 (14\%) enthesitis, and 24 (18.6\%) current moderate/severe psoriasis. Most of them had low or moderate disease activity and almost a quarter of them $(32 ; 24.8 \%)$ were taking a biologic.

The most prevalent comorbidities were: dyslipidaemia 103 patients $(79.8 \%)$, hypertension $67(51.9 \%)$, obesity $44(34.1 \%)$, diabetes $21(16.3 \%)$ and ischemic heart disease $15(11.6 \%)$. Almost a third of patients $(42,32.6 \%)$ suffered a cardiovascular event after their PsA diagnosis, of which heart attack 2 patients, stroke 4 , cardiac failure 4 and peripheral arterial disease one patient. Cardiovascular events correlated with smoking $(r=0.893, p<0.001)$ and current moderate/severe psoriasis $(r=0.218, p=0.013)$.

Regarding infectious comorbidities: 11 patients $(8.5 \%)$ had a history of tuberculosis after being diagnosed with PsA, 7 (5.4\%) chronic viral hepatitis, of which 4 with B virus and 3 with $C$ virus, and 5 patients $(3.9 \%)$ developed severe infections. Five patients $(3.9 \%)$ were diagnosed with neoplasia, but no correlation was identified with any of the clinical, biological or treatment related included variables. Only 11 patients $(8.5 \%)$ were diagnosed with depression, but the prevalence is probably underestimated, since not all patients were screened to this end.

Conclusions: PsA is associated with a high prevalence of comorbidities, especially cardiovascular diseases. This should be taken into consideration in the therapeutic and the global management of PsA patients.

References:

[1] Husni ME, Mease PJ. Managing comorbid disease in patients with psoriatic arthritis. Curr Rheumatol Rep 2010;12(4):281-7.

[2] Ogdie A, Yu Y, Haynes K, et al. Risk of major cardiovascular events in patients with psoriatic arthritis, psoriasis and rheumatoid arthritis: apopulation-based cohort study. Ann Rheum Dis 2015;74(2):326-32.

[3] Baillet A, Gossec L, Carmona L, et al. Points to consider for reporting, screening for and preventing selected comorbidities in chronic inflammatory rheumatic diseases in daily practice: a EULAR initiative. Ann Rheum Dis 2016;75(6):965-73

Disclosure of Interest: None declared

DOI: 10.1136/annrheumdis-2017-eular.5838

\section{AB1159 HIGH DOSE GLUCOCORTICOIDS AS A RISK FACTOR OF SIGMOID DIVERTICULITIS PERFORATIONS IN AUTOIMMUNE DISEASES}

T. Kuranobu, M. Ishitoku, T. Tokunaga, Y. Yoshida, S. Hirata, T. Nojima, E. Sugiyama. Department Clinical Immunology and Rheumatology, Hiroshima university hospital, Hiroshima, Japan

Background: It has been reported that glucocorticoids (GCs) and non-steroidal anti-inflammatory drugs (NSAIDs) might increase sigmoid diverticulitis perforations (SDPs) for rheumatoid arthritis patients, however, there are few previous reports referring to the relationship between SDPs and GCs in patients with systemic autoimmune diseases. We investigate relationship between SDPs and GCs in patients used GCs for not only rheumatic patients but also other autoimmune disease' sufferer.

SDPs and GCs

Objectives: To describe development of SDPs during high dose GC (over PSL $0.8 \mathrm{mg} / \mathrm{kg}$ equivalent) therapy for systemic autoimmune diseases in our department, additionally reviewing previous reports with regard to the relationship between SDPs and GCs.

Methods: 187 patients hospitalized in our department from April 2015 to December 2016 were retrospectively reviewed.

Results: Among 187 patients, 61 took high dose GCs, 29 took moderate dose GCs $(0.5-0.6 \mathrm{mg} / \mathrm{kg}$ PSL equivalent), 53 took low dose (less than $0.5 \mathrm{mg} / \mathrm{kg} \mathrm{PSL}$ equivalent), and 29 didn't take GCs. Four patients out of 61 who took high dose GCs developed SDPs (table). Nobody developed SDPs in moderate, low and 